\title{
Creep of recycled aggregate concrete: Experimental database and creep prediction model according to the fib Model Code 2010
}

\author{
Nikola Tošić ${ }^{\mathrm{a}, *}$, Albert de la Fuente ${ }^{\mathrm{b}}$, Snežana Marinković ${ }^{\mathrm{a}}$ \\ a University of Belgrade, Faculty of Civil Engineering, Bulevar kralja Aleksandra 73, 11000 Belgrade, Serbia \\ ${ }^{\mathrm{b}}$ Civil and Environmental Engineering Department, Universitat Politécnica de Catalunya (UPC), Jordi Girona 1-3, 08034 Barcelona, Spain
}

\section{H I G H L I G H T S}

- Experimental results database of recycled aggregate concrete (RAC) creep compiled.

- Differences between RAC and natural aggregate concrete (NAC) creep examined

- Application of fib Model Code 2010 creep model to RAC tested.

- Correction factor for calculating RAC creep using the fib Model Code 2010 proposed.

\section{A R T I C L E I N F O}

\section{Article history:}

Received 27 August 2018

Received in revised form 3 November 2018

Accepted 5 November 2018

Available online $\mathrm{xxxx}$

\section{Keywords:}

Recycled concrete aggregate

Recycled aggregate concrete

Creep

Creep correction coefficient

Database

Model Code

\section{A B S T R A C T}

Recycled aggregate concrete (RAC) is a promising solution to addressing the sustainability issues raised by concrete production. However, its long-term properties are not fully characterised, especially creep behaviour, which is significant for the design of RAC structures. This study presents the results of a meta-analysis of previously published research on the creep behaviour of recycled aggregate concrete (RAC). The main goal of the study is to formulate an analytic expression for the creep coefficient of RAC as an extension of the fib Model Code 2010 creep prediction model. A database of experimental results on the creep of RAC and companion natural aggregate concrete (NAC), produced with the same water-cement ratio, was compiled from available literature and using strict selection criteria. The database is comprised of results from 10 studies, 46 creep curves (14 NAC and 32 RAC) and 233 data points. Compared with companion NAC, RAC displays a larger creep coefficient; the difference between RAC and NAC increases with increasing recycled concrete aggregate (RCA) content and decreases with increasing RAC compressive strength. When predicting the creep coefficient of RAC using the fib Model Code 2010's creep prediction model, relative to the model's performance on companion NAC, the creep coefficient of $\mathrm{RAC}$ is underestimated. A correction coefficient for the creep coefficient of RAC, $\xi_{\mathrm{cc}, \mathrm{RAC}}$, is proposed for use with the fib Model Code 2010 model, dependent on RAC compressive strength and RCA replacement ratio. (c) 2018 Elsevier Ltd. All rights reserved.

\section{Introduction}

For concrete subjected to stress, the relation between stress and strain is a function of time, as shown schematically in Fig. 1. Under normal loading conditions, the instantaneous strain $\varepsilon_{\mathrm{ci}}\left(t_{0}\right)$ (where $t_{0}$ denotes the time of stress application) depends on the speed of load application and includes an elastic and plastic part. Since load application can only theoretically be truly instantaneous, this strain also includes some creep strain. After the application of stress $\sigma\left(t_{0}\right)$, the shrinkage strain, $\varepsilon_{\mathrm{cs}}$, continues to develop as shown

\footnotetext{
* Corresponding author.

E-mail addresses: ntosic@imk.grf.bg.ac.rs (N. Tošić), albert.de.la.fuente@upc.edu (A. de la Fuente), sneska@imk.grf.bg.ac.rs (S. Marinković)
}

by the dashed line in Fig. 1. At any time $t$, the strain in excess of both the instantaneous strain, $\varepsilon_{\mathrm{ci}}\left(t_{0}\right)$, and the shrinkage strain, $\varepsilon_{\mathrm{cs}}(t)$ is called the creep strain, $\varepsilon_{\mathrm{cc}}(t)$. If the stress is removed at a time $t_{1}$, a new instantaneous strain, $\varepsilon_{\mathrm{ci}}\left(t_{1}\right)$, and a delayed reversible strain, $\varepsilon_{\mathrm{r}}$, will occur.

The creep strain at the end of loading may be three to four times the instantaneous strain [1]. Similar to concrete shrinkage, the role of water is of primary importance for the development of the creep strain. Creep strain under conditions of no moisture exchange with the environment is called basic creep strain, $\varepsilon_{\mathrm{cbc}}$, whereas creep strain under moisture exchange with the environment is called drying creep strain, $\varepsilon_{\mathrm{cdc}}$. In cases with no exchange of water with the (ambient) environment (basic creep), the lower the evaporable water content in concrete, the lower the creep; however, with 

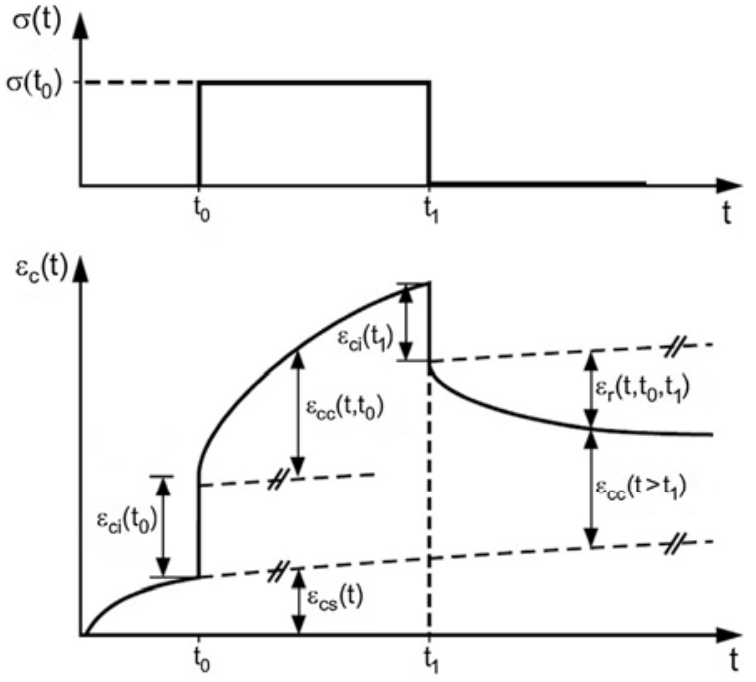

Fig. 1. Deformation of concrete under a sustained stress.

water exchange with the environment (drying creep), the greater the drying, the greater the creep [1]. In other words, creep is greater when there is water exchange with the environment (drying creep in excess of basic creep). This was first pointed out by Pickett [2].

Concrete creep was probably first observed at the beginning of the twentieth century by Hatt [3]. At that stage, beside empirical macroscale observations, it was not possible to offer physically meaningful interpretations of creep. However, by the middle of the century it was known that the process depended on the adsorption and desorption of water and that 'an analysis based on thermodynamics is especially instructive', as pointed out by Powers [4].

In the meantime, with the development of testing equipment, it became possible to study the phenomenon of creep on ever smaller scales. So far, the most detailed study is that by Vandamme and Ulm [5]. In it, the authors explain the nanogranular origin of creep. Since in concrete, it is the hydrated cement paste that displays creep behaviour-the aggregates mostly offer restraint-the authors performed nanoindentation tests of $\mathrm{C}-\mathrm{S}-\mathrm{H}$ since it is the major component contributing to the structure of the paste. The hypothesis of the authors is that C-S-H creep is 'likely due to the rearrangement of nanoscale particles around limit packing densities following the free-volume dynamics theory of granular physics' [5].

Theoretically as well, there have been many attempts at describing the complex phenomena of concrete creep. One of the most successful approaches has been the 'microprestress-solidifica tion' theory put forward by Bažant et al. [6]. The rationale behind the theory is that the justification for creep and the aging properties of concrete must be sought in changes in the microstructure, modelling the process of cement hydration by the gradual deposition of non-aging layers of new hydration products on the walls of capillary pores in the hardened cement paste [6]. This theory formed the basis of the B3 creep and shrinkage model [7] and, later, the improved B4 model [8].

Since creep depends on many factors such as aggregate stiffness, cement type and content, stress level, loading age, relative humidity (RH), member thickness and temperature, the most complex models for predicting creep behaviour of concrete, such as the aforementioned B4 model [8], require many input variables, e.g. knowing the full mix design of the concrete. This is not easily achieved in all practical settings and is suitable only for the most demanding design situations. Other models for predicting creep, such as the ACI 209R-92, Eurocode 2 and fib Model Code 2010 (MC2010) models [9-11] are suitable for practicing engineers as they are mostly based only on compressive strength, $f_{c}$, as an input and a limited number of other parameters such as loading age $t_{0}$, $\mathrm{RH}$ and member thickness.

However, even with their simplified theoretical backgrounds and often empirical approaches, these models show a satisfactorily good performance in predicting concrete creep, especially the fib Model Code 2010 creep model, which is the newest among those previously mentioned [12]. As in the case of shrinkage, what has enabled this is the availability of large databases of experimental results on which models can be tested and calibrated. Since the first databases in the 1960s for the first CEB-FIP Model Code [13] there were many updates and improvements. Currently, the largest database is the 'NU-ITI database on concrete creep and shrinkage' assembled in 2010-2013 at the Northwestern University's Infrastructure Technology Institute and freely available online [14].

The database contains approximately 1400 creep curves (divided relatively uniformly among 'total' or drying and basic creep curves). It should be noted that the results in the database are expressed in terms of creep compliance $J_{c}\left(t, t_{0}\right)$. For stress levels which do not exceed approximately $40 \%$ of concrete mean compressive strength, 'linear' theories of creep apply [15,16], i.e. concrete stress-dependent strain, $\varepsilon_{\mathrm{c} \sigma}$, is linearly related to stress through the compliance function $J_{c}\left(t, t_{0}\right)$ :

$$
\begin{aligned}
& \varepsilon_{c \sigma}\left(t, t_{0}\right)=\varepsilon_{c i}\left(t_{0}\right)+\varepsilon_{c c}\left(t, t_{0}\right)=\frac{\sigma_{c}\left(t_{0}\right)}{E_{c}}+\varphi_{c}\left(t, t_{0}\right) \cdot \frac{\sigma_{c}\left(t_{0}\right)}{E_{c}} \\
& \varepsilon_{c \sigma}\left(t, t_{0}\right)=\left(\frac{1+\varphi_{c}\left(t, t_{0}\right)}{E_{c}}\right) \sigma_{c}\left(t_{0}\right)=J_{c}\left(t, t_{0}\right) \cdot \sigma_{c}\left(t_{0}\right)
\end{aligned}
$$

where $E_{\mathrm{c}}$ is the concrete modulus of elasticity and $\varphi_{\mathrm{c}}\left(t, t_{0}\right)$ is the creep coefficient. However, the definition of creep compliance depends on the model in question. It is a mistake to directly compare creep coefficients obtained by different prediction models with reported 'experimental' creep coefficients (usually the ratio of creep-to-initial strain), because creep coefficients can be derived from creep compliance in different ways.

Although the NU-ITI database contains almost 800 creep curves of concretes containing some type of admixture or additive, there is still no information on the creep behaviour of recycled aggregate concrete (RAC), even though RAC produced with coarse recycled concrete aggregate (RCA) is one of the most studied and most promising green concretes. The aim of this study is to fill in this gap.

Recycling of concrete waste to produce RCA leaves RCA particles with a certain amount of 'residual cement mortar' attached to natural aggregate particles. This residual cement mortar is one of the defining characteristics of RCA, influencing most of its properties: density, water absorption, porosity, etc. As for creep behaviour of RAC produced with coarse RCA (particles larger than $4 \mathrm{~mm}$ ), residual cement mortar exerts its influence in complex ways: through affecting aggregate stiffness and the restraint it provides to creep as well as through the residual cement mortar and how much creep it already underwent in the original concrete [17].

Even though numerous researchers have studied the creep behaviour of RAC over the years, limited knowledge has been gained, mostly because the large number of influencing parameters can be properly assessed only with a large number of long-term studies. However, a few literature reviews already exist, with similar conclusions. Silva [18] studied the expected increase in RAC creep relative to companion natural aggregate concrete (NAC), produced with the same effective water-cement $(w / c)_{\text {eff }}$ ratio $(w / c$ ratio calculated without consideration of water added to compen- 
sate RCA absorption). According to his analysis, for RAC with $100 \%$ coarse RCA, the 95\% upper confidence limit for increase in creep compliance, creep coefficient and creep strain, relative to NAC, was $81 \%, 82 \%$ and $91 \%$, respectively. From this, Silva [18] proposed creep coefficient correction factors of $1.2,1.4$ and 1.8 for RAC with $20 \%, 50 \%$ and $100 \%$ of coarse RCA, respectively. These corrections are significantly greater than those proposed by RILEM [19] which are 1.0 and 1.25 for RAC with up to $20 \%$ and $100 \%$ coarse RCA, respectively.

Another important review study on RAC creep is the one by Lye et al. [20]. The authors first analysed current conclusions and prediction recommendations for RAC creep proposed by researchers and organizations. They found that these prediction recommendations typically propose $15-60 \%$ increase in creep for RAC with $100 \%$ coarse RCA relative to companion NAC, whereas for low replacement percentages, e.g. $20 \%$, usually no increase in creep is proposed. Then, they performed their own analysis and for results from 27 countries since 1984, found the average increase in creep of RAC with $100 \%$ coarse RCA to be $32 \%$ relative to companion NAC; for a $20 \%$ coarse RCA content, the increase was $20 \%$, contrary to prior findings [20]. The authors also made a diagram for an easy assessment of the necessary creep correction factor for RAC with respect to NAC as a function of RCA content and compressive strength. The diagram is intended for correcting Eurocode 2 creep coefficient predictions [20]. While they are easy to understand, the use of the proposed diagrams is not easily applicable to computerbased design and requires manual calculation.

As for modelling RAC creep, only a few authors had attempted to tackle this problem. Fan et al. [21] presented a possible model for predicting the increase in RAC creep relative to companion NAC. However, the authors' model is very intricate and has a downside of being based on companion NAC properties; hence, it is not a true 'design' model for RAC. Another attempt is the correction of the ACI 209R-92 model proposed by Fathifazl and Razaqpur [17]. In their proposal, the authors introduce a new correction coefficient multiplying the ultimate creep coefficient: the RCA coefficient $K_{\mathrm{RCA}}$. The derivation of this coefficient starts from the fact that RCA has several influences on RAC creep: it increases the fines and air content of RAC and its residual cement mortar has creep properties. Hence, 'the creep of RAC is a function of its residual mortar content and the extent of recoverable creep in that mortar' [17]. The authors hypothesize that the coefficient $K_{\mathrm{RCA}}$ is comprised of two other coefficients representing the influences of these two parameters. However, the practical application of this coefficient is also difficult since it requires sufficient knowledge about the used RCA in the design stage (e.g. the residual mortar content of RCA). Finally, Seara-Paz et al. [22] proposed a correction factor for the time evolution of the RAC creep coefficient. However, the proposed expression depends only on the concrete age and not on the RCA content of RAC. Furthermore, the expression is derived only from the authors' own experimental results and therefore needs further justification and verification on other results.

The first aim of this study is to compile a new database of experimental results on the creep behaviour of RAC and companion NAC using clear selection criteria. The second aim is to formulate an analytic expression for a correction factor for RAC creep coefficient that will represent an extension of the MC2010 creep model [11] through a statistical meta-analysis of the database. The reason for choosing MC2010 is the fact that it has a very advanced, yet simple creep prediction model. It is also a 'model code' for other national and international provisions and codes, e.g., MC2010 will form the basis of the new version of Eurocode 2. Additionally, MC2010 places a large accent on sustainability [11]; hence, new codes based on it must include constitutive models and design equations for RAC and not only limitations on RCA content or quality, which has mostly been the practice so far. The solutions proposed in this study present an advance in this direction.

\section{RAC creep database}

\subsection{Compilation of database}

As a first step in this study, a new database of experimental results on RAC and companion NAC creep was compiled. Although some authors have previously compiled similar databases $[18,20]$, a new one was created in this study with stricter criteria for choosing studies than previously used. First of all, since the aim of this study was not only to compare RAC and NAC creep, but also test the applicability of the MC2010 model, all data necessary for creep calculation had to be reported in the studies. The following criteria were selected:

- results are given on the shrinkage strain of RAC and companion NAC defined as having the same $(w / c)_{\text {eff }}$ ratio;

- 28-day compressive strength is provided along with the type of test specimen used for testing it;

- the $(w / c)_{\text {eff }}$ ratio is provided;

- water absorption (w.a.) of coarse aggregates is provided;

- any reactive additives, such as fly ash, are used in amounts smaller than $30 \%$ of cement weight;

- loading age of creep specimens $t_{0}$, their dimensions or notional size $h_{0}$ (two times the ratio of a cross-section's area to its perimeter in contact with the atmosphere, $2 \cdot A_{c}=u$ ), and ambient conditions during testing are provided;

- stress-to-strength at loading age ratio, $\sigma_{\mathrm{c}}\left(t_{0}\right) / f_{\mathrm{cm}}\left(t_{0}\right)$ is reported and is below 0.4 , i.e. concrete is supposed to exhibit linear creep behaviour;

- data for creep (creep coefficient, creep strain, specific creep, or creep compliance) is reported for at least two points in time, $t-t_{0}$, i.e. the results are given in the form of a 'time curve'.

The only assumption that was made was regarding the type of cement used: since it was found that a significant number of studies do not report it, in cases when data was missing, cement type was assumed to be $42.5 \mathrm{~N}$ for both RAC and NAC.

Special consideration was given to what should be the basis of comparison between RAC and NAC and the basis of MC2010 analysis. Different studies reported results in different forms, most often in the form of creep coefficient $\varphi_{\mathrm{c}}\left(t, t_{0}\right)$, creep strain $\varepsilon_{\mathrm{cc}}\left(t, t_{0}\right)$, or specific creep (creep strain divided by stress) $\varepsilon_{\mathrm{cc}}\left(t, t_{0}\right) / \sigma_{\mathrm{c}}\left(t_{0}\right)$. Since the aim of the study is to provide an analytic correction factor for RAC creep, the easiest way of 'intervening' in the model is at the level of creep coefficient. Hence, it was chosen as the basis of comparison and analysis. However, care needs to be taken about how MC2010 defines its creep coefficient, here labelled $\varphi_{\mathrm{MC}}\left(t, t_{0}\right)$. MC2010 defines creep compliance not according to Eq. (2) but as

$J_{c}\left(t, t_{0}\right)=\frac{1}{E_{c}\left(t_{0}\right)}+\frac{\varphi_{M C}\left(t, t_{0}\right)}{E_{c i}}$

where $E_{\mathrm{c}}\left(t_{0}\right)$ is the modulus of elasticity at loading age $t_{0}$ and $E_{\mathrm{ci}}$ is the modulus of elasticity after 28 days. If Eq. (2) is rewritten using Eq. (3), it becomes

$\varepsilon_{c \sigma}\left(t, t_{0}\right)=\left(\frac{1}{E_{c}\left(t_{0}\right)}+\frac{\varphi_{M C}\left(t, t_{0}\right)}{E_{c i}}\right) \cdot \sigma_{c}\left(t_{0}\right)$

Since $\varepsilon_{\mathrm{c} \sigma}\left(t, t_{0}\right)$ is the sum of initial and creep strain, $\varepsilon_{\mathrm{ci}}\left(t_{0}\right)$ and $\varepsilon_{\mathrm{cc}}\left(t, t_{0}\right)$, respectively, Eq. (4) becomes

$\varepsilon_{c i}\left(t_{0}\right)+\varepsilon_{c c}\left(t, t_{0}\right)=\frac{\sigma_{c}\left(t_{0}\right)}{E_{c}\left(t_{0}\right)}+\frac{\varphi_{M c}\left(t, t_{0}\right)}{E_{c i}} \cdot \sigma_{c}\left(t_{0}\right)$ 
If a study reports the experimental creep coefficient, it does so in the following form:

$\varphi_{\exp }\left(t, t_{0}\right)=\frac{\varepsilon_{c c}\left(t, t_{0}\right)}{\varepsilon_{c i}\left(t_{0}\right)}$

After applying Eq. (5), the following relationship is obtained:

$\varphi_{M C}\left(t, t_{0}\right)=\varphi_{\text {exp }}\left(t, t_{0}\right) \cdot \frac{E_{c i}}{E_{c}\left(t_{0}\right)}$

As can be seen, the experimental and MC2010 creep coefficients are identical only when the loading age is 28 days (which is the case in the majority of studies).

If specific creep is reported, i.e. $\varepsilon_{\mathrm{cc}}\left(t, t_{0}\right) / \sigma_{\mathrm{c}}\left(t_{0}\right)$, then from Eq. (5) it follows that

$\varphi_{M C}\left(t, t_{0}\right)=E_{c i} \cdot \frac{\varepsilon_{c c}\left(t, t_{0}\right)}{\sigma_{c}\left(t_{0}\right)}$

Similarly, if only creep strain $\varepsilon_{c c}\left(t, t_{0}\right)$ is reported, then, if the stress or stress-to-strength ratio and strength are known, the MC2010 creep coefficient can be calculated using Eq. (8).

The compilation of the databases was carried out by analysing studies reported in previous literature reviews $[18,20]$ and applying the stated criteria. Finally, 10 studies entered the database (describing 9 experimental programmes - two studies had complementing data about one set of experiments) $[17,21,23-30]$ with a total of 46 creep time curves (14 NAC and $32 \mathrm{RAC}$ ), consisting of 233 data points. All of the studies dealt only with total creep, i.e. there was no separation into basic and drying components.

In comparison with previous databases $[18,20]$, this one is much smaller because of the stricter selection criteria. For example, in the review by Lye et al. [20], a lot of considered studies were conference proceedings which usually lack some key information such as ambient conditions, loading age, or water absorption of RCA; this is acknowledged by the authors [20].

Another very important difference between this database and previous ones is the fact that creep time curves are the basis of analysis and not individual, 'final' values; hence, the request for at least two points in time being reported for each tested specimen. This enables a more in-depth analysis and testing a wider range of creep behaviour. In all of the studies except one [29], data is reported in graphical form. In order to extract the values, the figures were imported into a CAD software, scaled and the values were read from the graphs. Creep time curves were obtained by sampling results as equally as possible from every 'time decade' covered (1-9.9, 10-99.9, 100-999.9, 1000 - days) and by sampling as equally as possible between different experiments, e.g., 28, 90, 180 days under loading. RAC and companion NAC creep time curves from the same experiment were always sampled at the same times. Five studies reported results as specific creep, one study as creep strain and four studies as experimental creep coefficient.

The database is available as an Excel file as Supplementary material. The ranges of the most important parameters are given in Table 1.

As can be seen from the database, the parameter ranges between RAC and companion NAC are very similar, except for water absorption of aggregates. The database covers the entire range of 'normal strength' concretes (20-60 MPa). The water absorption values for RCA are between $3.3 \%$ and $9.0 \%$ which is a wide enough range to cover different quality RCA. In fact, of the nine experimental programmes in the database, in two cases $[28,30]$ the origin of RCA were recycled laboratory specimens, in five studies the origin of RCA was concrete waste obtained from a commercial recycling plant $[17,24-27,29]$ and two studies provided no data on RCA origin $[21,23]$. However, in all of the studies
RCA was composed of $100 \%$ crushed concrete waste, except for the RCA in the study by Seara-Paz [29] which was composed of approximately $62 \%$ of crushed concrete waste, $25 \%$ of natural aggregate particles, $10 \%$ of asphalt and $3 \%$ of ceramic waste.

The loading age is 28 days in all studies except one [29]. The maximum duration of tests in the database is 1000 days, whereas the average duration is approximately 350 days, and the mode is only 100 days. Notional size is in a narrow range of small values, $50-75 \mathrm{~mm}$; this is important when making any conclusions since creep kinetics will not scale linearly to full-scale structural members with larger notional sizes. Finally, $\mathrm{RH}$ values are all above $50 \%$ and lie in a narrow range (50-77\%).

For RAC, most of the data is for replacement ratio of $26-50 \%$ followed by $76-100 \%$ (this range actually only contains data for $100 \%$ ). The range $51-75 \%$ has the least number of data points from only two experimental programmes $[17,21,25]$ which could carry additional bias in further discussions. Nonetheless, the database contains sufficient data to proceed with analyses and provided as Supplementary material, it constitutes an important contribution for the research community, which other researchers can improve in the future.

\subsection{Comparison of RAC and companion NAC}

Next, a direct comparison of the MC2010 experimental creep coefficient for RAC and companion NAC was performed to assess whether there are differences between them and if there are any, what the influencing parameters are.

The reported data (experimental creep coefficient, specific creep, or creep strain) were used to calculate the experimental MC2010 creep coefficient', $\varphi_{\text {MC,exp }}\left(t, t_{0}\right)$, using Eqs. (7) and (8). After calculating the experimental MC2010 creep coefficient for all 233 data points, a ratio of RAC-to-NAC experimental MC2010 creep coefficient, $\varphi_{\mathrm{MC}, \exp , \mathrm{RAC}} / \varphi_{\mathrm{MC}, \exp , \mathrm{NAC}}$, was determined for every data point (each RAC was compared with its own companion NAC): in total, there were $166 \varphi_{\mathrm{MC}, \exp , \mathrm{RAC}} / \varphi_{\mathrm{MC}, \text { exp,NAC }}$ ratios (the total number of data points for RAC as some NAC where companion mixtures for multiple RAC). First, the statistical descriptors of the $\varphi_{\mathrm{MC} \text {,exp,RAC }}$ $\varphi_{\mathrm{MC}, \text { exp,NAC }}$ ratio were calculated - its mean and coefficient of variation $(\mathrm{CoV})$. They are provided in Table 2 under 'full database'. The mean ratios are practically constant for RCA contents below 50\%, then drop sharply to approximately 1 for $51-75 \%$ of RCA, and rise again sharply to 1.63 for $76-100 \%$ of RCA; all ranges show very large CoVs. The small mean value in the $51-75 \%$ range can be attributed to the fact that this range contains the smallest number of data points and that it contains results from studies in which the Equivalent Mortar Volume mix design methodology is used [17,25] - this mix design methodology was shown to lead to RAC creep behaviour comparable to companion NAC. Nonetheless, the results point to a definite effect of RCA on creep and to a larger creep of RAC compared with companion NAC.

Next, for each RCA replacement percentage, outlier values were identified using a box-and- whiskers technique: 11 were found in total, 2 values for $20 \%$ and $50 \%$ of RCA and 7 values for $100 \%$ of RCA. Not considering these outliers, statistical descriptors of the database are given in Table 2 under 'No RAC/NAC outliers'. A significant decrease in mean values and CoVs for all ranges except $51-75 \%$ (which contained no outliers) can be seen. Nonetheless, disregarding the $51-75 \%$ range, the $\varphi_{\mathrm{MC}, \exp , \mathrm{RAC}} / \varphi_{\mathrm{MC} \text {,exp,NAC }}$ ratio seems to increase with increasing RCA content.

In principle, these differences between the creep coefficient of RAC and companion NAC can originate from (1) differences in the magnitude of creep and (2) differences in creep development over time. An illustration of this, at the level of creep compliance, is provided in Fig. 2. On the left side, 'vertical scaling' of creep compliance is given: the kinetics of creep compliance evolution with 
time remain identical, only the magnitude of creep changes. This is evidenced by the vertical grey arrows which indicate the increase after vertical scaling - the size of the arrows increases because they are always an identical fraction of the original creep compliance value. On the right side of Fig. 2, 'horizontal scaling' of creep compliance curves is presented. In this case, the horizontal arrows indicating scaling have a constant length, i.e. every value of the original compliance is translated into an earlier or later time, always by the same time increment in a logarithmic scale.

Hence, the $\varphi_{\mathrm{MC}, \exp , \mathrm{RAC}} / \varphi_{\mathrm{MC}, \exp , \mathrm{NAC}}$ ratio can indicate both types of differences between RAC and companion NAC creep. In order to assess 'horizontal' differences between RAC and companion NAC creep, individual creep curves must be checked for trends in the evolution of the $\varphi_{\mathrm{MC}, \exp , \mathrm{RAC}} / \varphi_{\mathrm{MC} \text {,exp,NAC }}$ ratio within individual creep curves. The analysis was performed on the compiled database by looking at the evolution of the $\varphi_{\mathrm{MC}, \exp , \mathrm{RAC}} / \varphi_{\mathrm{MC}, \exp , \mathrm{NAC}}$ ratio for individual creep curves and by determining its CoV for individual creep curves. No trend could be observed since the $\varphi_{\mathrm{MC} \text {,exp,RAC }} / \varphi_{\mathrm{MC} \text {,exp,NAC }}$ ratio either remained stable over time or changed in a random manner. Furthermore, the average $\mathrm{CoV}$ of the $\varphi_{\mathrm{MC}, \exp , \mathrm{RAC}} / \varphi_{\mathrm{MC} \text {,exp, }}$ NAC ratio for individual creep curves was only $7.4 \%$, indicating its high uniformity for individual creep curves. These results indicate that there is no evidence for the need of horizontal scaling in the compiled database, and only vertical scaling of creep magnitude (creep coefficient) should be considered in the following analysis. This does not mean that 'horizontal' differences between RAC and companion NAC do not exist; however, without more experimental results which separate creep into basic and drying components, no definite conclusion can be drawn. Furthermore, since horizontal scaling is most easily detected early after loading (as seen in Fig. 2, between 1 and 200 days, the ratio between the curves is almost constant), measurements in future studies should begin as early as possible and results should be provided in numerical form, or graphically by plotting results on a logarithmic time scale.

All $166 \varphi_{\mathrm{MC}, \exp , \mathrm{RAC}} \varphi_{\mathrm{MC} \text { exp,NAC }}$ ratios are plotted versus RCA percentage in Fig. 3. Most of the data is for RCA percentages of $20 \%$, $50 \%$ and $100 \%$. The $\varphi_{\text {MC,exp,RAC }} / \varphi_{\text {MC,exp,NAC }}$ ratios marked with a circle are the outlier values previously identified (three of them are larger than 3 and are not shown on the graph but indicated with the arrow). The large variability of the data can clearly be seen from the figure. The very large scatter of the data is also visible when looking at the relation between the $\varphi_{\mathrm{MC}, \text { exp,RAC }} / \varphi_{\mathrm{MC}, \text { exp,NAC }}$ ratio and RAC compressive strength, $(w / c)_{\text {eff }}$ ratio and RCA water absorption (w.a.) shown in Fig. 4 for the 155 values in the database without outliers. All three graphs show a very high scatter of results.

Although creep of concrete, including RAC, depends on numerous factors, the current database does not contain sufficient data to reliably identify the effects of all influencing parameters. For example, the creep prediction model B4 [8] requires as input the $w / c$ ratio, amount of cement and aggregate-cement ratio - these are definitely direct influencing parameters for concrete creep, but it is another question whether they are readily available to an engineer in the design stage. It is therefore sometimes more instructive to adopt more of an 'engineering' or 'common sense' approach in identifying and choosing influencing parameters for prediction models. The parameters which it is most reasonable to know at the design stage, and which, by proxy, cover many other parameters that affect the difference between NAC and RAC creep, are the RAC compressive strength, $f_{\mathrm{cm}}(\mathrm{MPa})$ and RCA content, $R C A \%$ (\%). These are the parameters on which the focus of further analysis should lie.

\section{Creep coefficient calculation using the fib Model Code 2010}

\subsection{Fib Model Code 2010 performance on NAC}

Beside only directly comparing the creep behaviour of RAC and companion NAC, which was already done in previous literature reviews, this paper aims at testing the applicability of the MC2010 creep prediction model on RAC. However, before this can be done, the model's performance on NAC must be known. For this purpose, the much larger NU-ITI database can be used [14].

There are several studies which test the performance of MC2010 on the full NU-ITI database, comparing it with other models such as the B4 model [12,31]. Although they note the good performance of the model, in terms of various statistical descriptors, they mostly test the MC2010 model on the full NU-ITI database which also contains high-strength concretes and concretes with high percentages of admixtures and additives - something that is not reflected in the mixtures in the current database. Hence, in this study, the NU-ITI database with its original 1403 experimental creep compliance curves was filtered using similar criteria as the RAC database in order to obtain a large number of NAC with appropriate properties. The chosen criteria were the following:

- only total creep compliance curves considered;

- compressive strength between 20 and $60 \mathrm{MPa}$;

- cement type specified;

- content of additives below $30 \%$ of cement weight;

- creep specimen size specified;

- loading age reported;

- stress-to-strength at loading age ratio reported, above 0.1 and below 0.4 ;

- RH specified and below 100\% (drying).

After filtering the database according to these criteria 105 creep compliance curves remained with 2212 data points. The range of the data was 20-59 MPa for compressive strength, 23.5-257.1 for notional size, $47.5-75 \%$ for $\mathrm{RH}, 7-90$ days for $t_{0}, 1-11076$ days for $t-t_{0}$ and $0.12-0.40$ for $\sigma_{\mathrm{c}}\left(t_{0}\right) / f_{\mathrm{cm}}\left(t_{0}\right)$.

Since the NU-ITI database only reports creep compliance $J_{c}\left(t, t_{0}\right)$ as experimental values, $J_{\text {exp }}$, this was the basis of analysis. Creep compliance was calculated using Eq. (3). Since the modulus of elasticity was not reported for the majority of the studies, in order to retain consistency, it was calculated from the 28-day compressive strength for all studies, according to the MC2010 prediction formula:

Table 1

Range of parameters in the database.

\begin{tabular}{|c|c|c|c|c|c|c|c|c|c|c|c|}
\hline & & No. of curves & No. of points & $f_{\mathrm{cm}}(\mathrm{MPa})$ & $w / c(-)$ & w.a. (\%) & $t-t_{0}$ (days) & $t_{0}$ (days) & $\sigma_{\mathrm{c}}\left(t_{0}\right) / f_{\mathrm{cm}}\left(t_{0}\right)(-)$ & $h_{0}(\mathrm{~mm})$ & $R H(\%)$ \\
\hline NAC & & 14 & 67 & $20-61$ & $0.45-0.73$ & $0.3-2.0$ & $1-1000$ & $28-42$ & $0.20-0.40$ & $50-75$ & $50-77$ \\
\hline \multirow[t]{4}{*}{ RAC } & $1-25 \%$ & 5 & 29 & $40-54$ & $0.50-0.65$ & $5.2-5.6$ & $7-1000$ & $28-42$ & $0.26-0.35$ & 75 & $50-75$ \\
\hline & $26-50 \%$ & 12 & 70 & $31-52$ & $0.48-0.65$ & $3.5-9.0$ & $1-1000$ & $28-42$ & $0.20-0.40$ & $50-75$ & $50-75$ \\
\hline & $51-75 \%$ & 4 & 18 & $37-45$ & $0.45-0.50$ & $3.3-8.1$ & $7-400$ & 28 & $0.30-0.40$ & $50-75$ & $50-65$ \\
\hline & $76-100 \%$ & 11 & 49 & $19-54$ & $0.45-0.75$ & $3.3-5.6$ & $6-1000$ & $28-42$ & $0.25-0.40$ & $50-75$ & $50-77$ \\
\hline
\end{tabular}


Table 2

Statistical descriptors of the $\varphi_{\mathrm{MC}, \text { exp,RAC }} / \varphi_{\mathrm{MC}, \text { exp,NAC }}$ ratio.

\begin{tabular}{llllll}
\hline \multirow{2}{*}{ RCA\% } & \multicolumn{2}{l}{ Full database } & & \multicolumn{2}{l}{ No RAC/NAC outliers } \\
\cline { 2 - 3 } \cline { 5 - 6 } & $\mu$ & $\operatorname{CoV}(\%)$ & & $\mu$ & $\operatorname{CoV}(\%)$ \\
\hline $1-25$ & 1.26 & 37.1 & 1.16 & 15.9 \\
$26-50$ & 1.21 & 29.0 & & 1.18 & 22.3 \\
$51-75$ & 0.97 & 29.3 & & 0.97 & 29.3 \\
$76-100$ & 1.63 & 45.6 & & 1.39 & 17.6 \\
\hline
\end{tabular}

$E_{c i}=21500 \cdot \alpha_{E} \cdot\left(\frac{f_{c m}}{10}\right)^{1 / 3}$

where $E_{\mathrm{ci}}$ is the 28-day modulus of elasticity in MPa and $\alpha_{\mathrm{E}}$ is a coefficient dependent on the aggregate type (1.0 for quartzite, 1.2 for basalt, 0.9 for limestone and 0.7 for sandstone aggregates). Since it was not reported for most of the studies, it was taken as 1.0 for all data points.

The time evolution of the modulus of elasticity is given by the following expression:

$E_{c}\left(t_{0}\right)=E_{c i} \cdot \sqrt{\beta_{c c}(t)}$

$\beta_{c c}(t)=\exp \left\{s \cdot\left[1-\sqrt{\frac{28}{t}}\right]\right\}$

where $s$ is a cement type-dependent coefficient: $0.38,0.25$ and 0.20 for slow, normal and rapid hardening cements, respectively.

As for the MC2010 creep coefficient, it is defined as the sum of its basic and drying components, $\varphi_{\mathrm{bc}}\left(t, t_{0}\right)$ and $\varphi_{\mathrm{dc}}\left(t, t_{0}\right)$ :

$\varphi_{M C}\left(t, t_{0}\right)=\varphi_{b c}\left(t, t_{0}\right)+\varphi_{d c}\left(t, t_{0}\right)$

Each of the two components is defined as a product function of a 'final' creep coefficient (dependent on parameters such as compressive strength, notional size and relative humidity) and a time development function. The basic creep coefficient is modelled as

$\varphi_{b c}\left(t, t_{0}\right)=\beta_{b c}\left(f_{c m}\right) \cdot \beta_{b c}\left(t, t_{0}\right)$

and the drying creep coefficient as

$\varphi_{d c}\left(t, t_{0}\right)=\beta_{d c}\left(f_{c m}\right) \cdot \beta(R H) \cdot \beta_{d c}\left(t_{0}\right) \cdot \beta_{b c}\left(t, t_{0}\right)$

with the remaining MC2010 expressions provided in Table 3.

Since the analysis is based on individual creep compliance curves and since the 'sampling' of the data is unequal, i.e. the database is biased towards shorter times under load, special statistical descriptors need to be used which provide weighting of the data in order to eliminate such biases. One possible set of indicators, which was used in this study, are the CEB statistical indicators proposed by Müller and Hilsdorf in 1990 [32]: the mean deviation $M_{\mathrm{CEB}}$ and the coefficient of variation $V_{\mathrm{CEB}}$. The indicators are calculated for six time ranges: $0-10,11-100,101-365,366-730$ 731-1095 and 1095 - days.

The CEB mean deviation indicates 'systematic overestimation or underestimation of a given model' [32]:

$M_{i}=\frac{1}{n} \cdot \sum_{j=1}^{n} \frac{C_{i j}}{O_{i j}}$

where $n$ is the number of values in a considered time interval $i, C_{i j}$ is the predicted value of creep compliance for the $i$-th data point in data set $j$ and $O_{i j}$ is the measured value of creep compliance for the $i$-th data point in data set $j$. Then,

$M_{C E B}=\frac{\sum_{i=1}^{n} M_{i}}{N}$

where $N$ is the total number of time intervals considered.

The CEB coefficient of variation is calculated using the following expressions:

$\bar{O}_{i}=\frac{1}{n} \cdot \sum_{j=1}^{n}\left(O_{i j}\right)$

$V_{i}=\frac{1}{O_{i}} \cdot \sqrt{\frac{1}{n-1} \cdot \sum_{j=1}^{n}\left(C_{i j}-O_{i j}\right)^{2}}$

$V_{C E B}=\sqrt{\frac{1}{N} \cdot \sum_{i=1}^{N} V_{i}^{2}}$

After calculating these indicators for the full 2212 data points, a CEB mean deviation of 1.06 and CEB CoV of $37.8 \%$ were obtained. Although the obtained CEB CoV is very high, the mean deviation is a good result. Again, outliers were eliminated using a box-andwhiskers technique for each time interval, leaving 2053 data points for which a CEB mean deviation of 0.98 and CEB CoV of $27.6 \%$ were calculated. The results show an excellent performance of the MC2010 creep model on NAC.

\subsection{Fib Model Code 2010 mathematical form verification for RAC}

Hubler et al. [33] point out that the first step in an analysis of a creep prediction model must be the consideration of the form of the creep compliance function, i.e. its ability to qualitatively capture and describe the development of compliance over time.

Hence, in this step, a verification of MC2010's ability of describing the evolution of RAC creep compliance was sought. Experimental compliances were determined from the study by Seara-Paz [29] - for two NAC mixtures (H50-0, H65-0), two mixtures with $50 \%$ RCA (H50-50, H65-50) and two mixtures with $100 \%$ RCA (H50100, H65-100); where H50 and H65 represent mixes with a ( $w /$
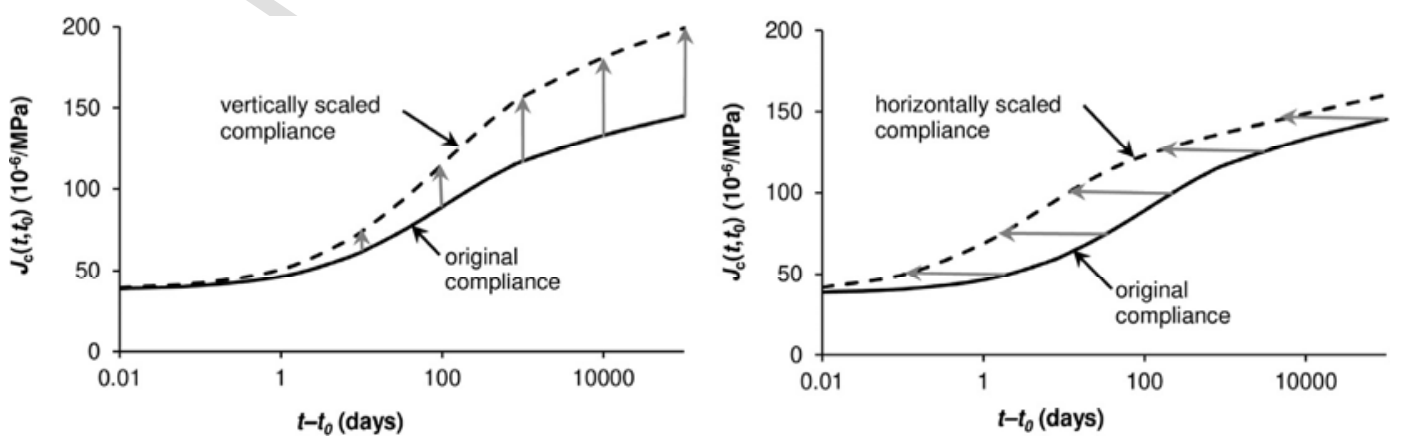

Fig. 2. Differences between vertical (left) and horizontal (right) scaling of creep compliance curves. 


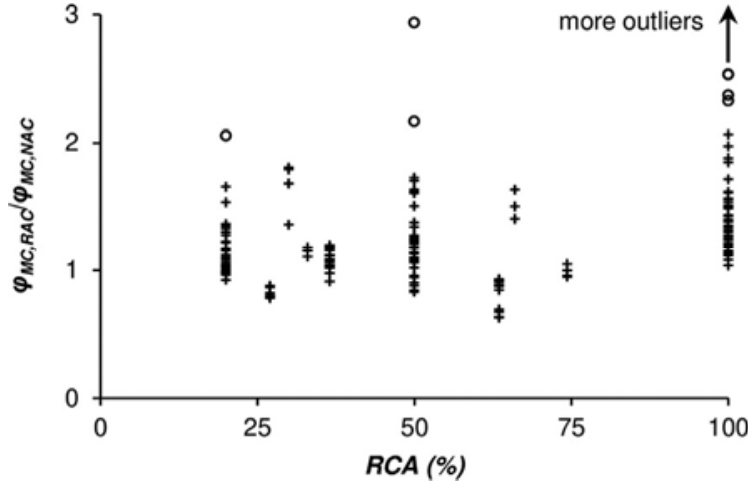

Fig. 3. Distribution of the RAC-to-NAC experimental MC2010 creep coefficient

c) eff ratio of 0.50 and 0.65 , respectively. The mixes cover a wide range of compressive strength 32-60 MPa and RCA content, as well as time under load (1000 days); hence, they were chosen as representative results for this step of the analysis. Since all values were reported (modulus of elasticity and creep coefficient), compliance was calculated according to Eq. (3). Because the form verification of the model was the goal, default values of free parameters had to be recalibrated to best fit the experimental data (minimize the CEB mean deviation and CEB CoV). This was done using calibration coefficients $\xi_{\mathrm{bc} 1}, \xi_{\mathrm{bc} 2}, \xi_{\mathrm{dc} 1}$ and $\xi_{\mathrm{dc} 2}$ applied to Eqs. (12), (15) and (20), as proposed by Project Team 1, currently developing the revision of Eurocode 2 [34].

$\varphi_{M C}\left(t, t_{0}\right)=\xi_{b c 1} \cdot \varphi_{b c}\left(t, t_{0}\right)+\xi_{d c 1} \cdot \varphi_{d c}\left(t, t_{0}\right)$

$\beta_{b c}\left(t, t_{0}\right)=\ln \left(\left(\frac{30}{t_{0}}+0.035\right)^{2} \cdot \frac{\left(t-t_{0}\right)}{\xi_{b c 2}}+1\right)$

$\beta_{d c}\left(t, t_{0}\right)=\left[\frac{\left(t-t_{0}\right)}{\beta_{h} \cdot \xi_{d c 2}+\left(t-t_{0}\right)}\right]^{\gamma\left(t_{0}\right)}$

Calibration coefficients $\xi_{\mathrm{bc} 1}$ and $\xi_{\mathrm{dc} 1}$ are vertical scaling factors since they simply multiply the calculated creep coefficient value, whereas calibration coefficients $\xi_{\mathrm{bc} 2}$ and $\xi_{\mathrm{dc} 2}$ are horizontal scaling factors since they alter the parameters of the basic and drying creep time evolution functions $\beta_{\mathrm{bc}}\left(t, t_{0}\right)$ and $\beta_{\mathrm{dc}}\left(t, t_{0}\right)$, respectively.

After calculating the creep compliance of the six considered curves, even without calibration, four of them had a CEB mean deviation between 0.98 and 1.02 and a CEB CoV between $5.3 \%$ and $7.6 \%$. For the remaining two curves (H50-0 and $\mathrm{H} 50-100$ ), the coefficients $\xi_{\mathrm{bc} 1}, \xi_{\mathrm{bc} 2}, \xi_{\mathrm{dc} 1}$ and $\xi_{\mathrm{dc} 2}$ were determined using the least squares method as $1.0,1.0,1.1,1.5$, and $0.9,0.8,1.3,1.5$, respectively. This way, all six curves had a CEB mean deviation between 0.98 and 1.02 and a CEB CoV between $5.3 \%$ and $9.4 \%$, which is an excellent result, Fig. 5. As can be seen, MC2010 can describe equally well the time evolution of NAC and RAC creep compliance. Hence, the model is adequate for use on RAC.

This analysis was only used to demonstrate that the mathematical form of MC2010 can adequately model the time evolution of RAC creep. In the following section the global behaviour of MC2010 on a database of results is performed with default parameter values of MC2010. In other words, none of the calibration coefficients from this section were used in the following analyses, i.e. coefficients $\xi_{\mathrm{bc} 1}, \xi_{\mathrm{bc} 2}, \xi_{\mathrm{dc} 1}$ and $\xi_{\mathrm{dc} 2}$ were taken equal to 1 .

\subsection{Fib Model Code 2010 overall performance on RAC}

The second step in the analysis of the applicability of MC2010's creep prediction model to RAC was to calculate $\varphi_{\mathrm{MC} \text {,calc }}$, the calculated MC2010 creep coefficient, for all results in the RAC database with previously eliminated outliers (67 NAC and 155 RAC data points). Then, the ratio of calculated-to-experimental MC2010 creep coefficient, $\varphi_{\mathrm{MC} \text {,calc }} / \varphi_{\mathrm{MC} \text {,exp }}$, was analysed again using the CEB mean deviation and CEB CoV as statistical indicators. The results, classified according to RCA percentage, are presented in Table 4. The column 'Full database' shows results for the original database and column 'No calc/exp outliers' shows the results with eliminated outlying $\varphi_{\mathrm{MC} \text {,calc }} / \varphi_{\mathrm{MC}, \exp }$ ratios (7 in total, 4 NAC and 3 RAC).

First, eliminating outlying $\varphi_{\mathrm{MC}, \text { calc }} / \varphi_{\mathrm{MC}, \exp }$ ratios decreases the statistical indicators the most for NAC. Second, the CEB mean deviation for NAC is 1.11 (for the 'No calc/exp outliers' database), higher than obtained on the filtered NU-ITI database (0.98). However, considering the CEB CoV of both this sample (40.3\%) and the NU-ITI database (27.6\%), a 'subset' of the NU-ITI database with these values of indicators is plausible.

Looking at Table 4, it seems as though MC2010 predicts the RAC creep coefficient very well (except for RAC with $51-75 \%$ of RCA). However, this would be a wrong conclusion since MC2010's performance on RAC must be compared with its performance on companion NAC, for which it overestimates the creep coefficient by $10 \%$ on average. As shown in Section 2.2, RAC has systematically higher creep compared with companion NAC. Since MC2010 only uses compressive strength as a mixture-related parameter, one explanation could be that RAC actually has, on average, a lower compressive strength and this leads to different predictions of the creep coefficient. However, a comparison of compressive strengths of mixes in the database revealed that the $f_{\mathrm{cm}, \mathrm{RAC}} / f_{\mathrm{cm}}$, NAC ratio had a mean value of exactly 1.0 with a CoV of $17.1 \%$. This was largely due to the fact that RAC mixes from studies by Fathifazl et al. $[17,25]$ were prepared using the Equivalent Mortar Volume mix design, which led to almost 30\% higher strengths of RAC compared with companion NAC; thus increasing the mean $f_{\mathrm{cm}, \mathrm{RAC}} / f_{\mathrm{cm}}$, NAC ratio for the database to 1.0 .

Fig. 6 presents a scatter plot of the filtered RAC and companion NAC database as calculated vs. measured values. The full black
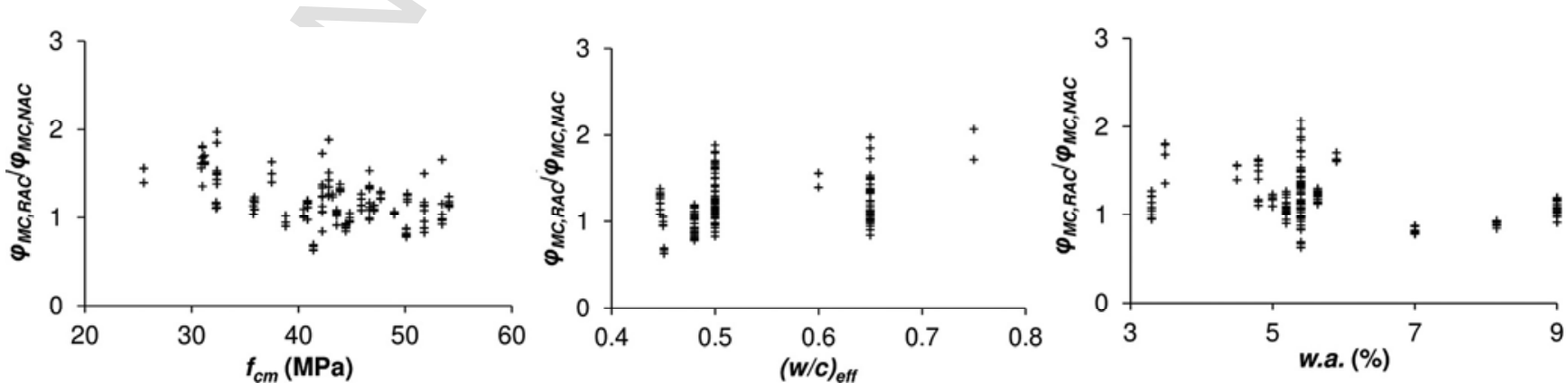

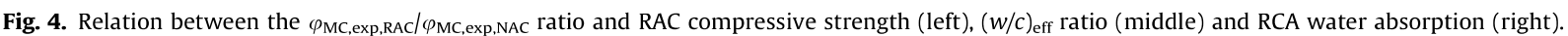


Table 3

MC2010 creep prediction expressions.

\begin{tabular}{ll}
\hline Equation & MC2010 expressions \\
\hline$(15)$ & $\beta_{b c}\left(f_{c m}\right)=\frac{18}{\left(f_{c m}\right)^{0.7}}$ \\
$(16)$ & $\beta_{b c}\left(t, t_{0}\right)=\ln \left(\left(\frac{30}{t_{0}}+0.035\right)^{2} \cdot\left(t-t_{0}\right)+1\right)$ \\
$(17)$ & $\beta_{d c}\left(f_{c m}\right)=\frac{412}{\left(f_{c m}\right)^{1.4}}$ \\
$(18)$ & $\beta(R H)=\frac{1-\frac{R H}{100}}{\sqrt[3]{0.1 \cdot \frac{h_{0}}{100}}}$ \\
$(19)$ & $\beta_{d c}\left(t_{0}\right)=\frac{1}{0.1+t_{0}^{2}}$ \\
$(20)$ & $\beta_{d c}\left(t, t_{0}\right)=\left[\frac{\left(t-t_{0}\right)}{\beta_{h}+\left(t-t_{0}\right)}\right]$ \\
$(21)$ & $\gamma\left(t_{0}\right)=\frac{1}{2.3+\frac{35}{\sqrt{t_{0}}}}$ \\
$(22)$ & $\beta_{h}=1.5 \cdot h_{0}+250 \cdot \alpha_{f_{c m}} \leq 1500 \cdot \alpha_{f_{c m}}$ \\
$(23)$ & $\alpha_{f_{c m}}=\left(\frac{35}{f_{c m}}\right)^{0.5}$ \\
\hline
\end{tabular}

lines represent mean lines, the full grey lines represent the equality line, and the dashed black lines represent 5 and 95 percentile boundaries for the data. The NAC scatter plot is relatively symmetrical with the mean line close to the equality line. The RAC scatter plot is less symmetrical with numerous points along the 5 percentile line, further enforcing the conclusion that MC2010 underestimates the creep coefficient of RAC compared with NAC.

Hence, the difference in creep coefficient predictions must stem from the higher magnitude of RAC creep and this means that MC2010 actually underestimates the RAC creep coefficient. It must therefore be corrected in a way that will lead to the CEB mean deviation and CEB CoV being equal for RAC and companion NAC. As shown in the discussion in Section 2.2, RAC creep should only be vertically scaled since no need for horizontal scaling could be identified on the compiled database.

\section{RAC creep coefficient correction factor for the fib Model Code 2010}

As stated in the introduction, the main goal of this study was to formulate an analytic expression for an RAC creep coefficient correction factor as an extension of the MC2010 creep prediction model. Since the database used in this study only contains results of total creep, it was only possible to propose a global correction factor $\xi_{\mathrm{cc}, \mathrm{RAC}}$ as follows:

$\varphi_{M C, R A C}\left(t, t_{0}\right)=\xi_{c c, R A C} \cdot \varphi_{M C}\left(t, t_{0}\right)$

where $\varphi_{\mathrm{MC}}\left(t, t_{0}\right)$ is the creep coefficient calculated according to MC2010 (as for any NAC). In principle, this approach is similar to the one by Lye et al. [20], however, this correction factor is for MC2010 and will be provided in analytic form. The proposed coefficient $\xi_{\mathrm{cc}, \mathrm{RAC}}$ is a vertical scaling factor and the adopted approach is essentially equal to adopting calibration coefficients $\xi_{\mathrm{bc} 1}$ and $\xi_{\mathrm{dc} 1}$ in Eq. (29) as equal, i.e. basic and drying creep coefficients are equally vertically scaled. Since there are not enough results for separate assessments of both creep components, this approach is justified, although it may potentially lead to non-unique solutions: $\varphi_{\mathrm{MC}, \mathrm{RAC}}\left(t, t_{0}\right)$ obtained using $\xi_{\mathrm{cc}, \mathrm{RAC}}$ and Eq. (32) can also be obtained using Eq. (29) and several different combinations of coefficients $\xi_{\mathrm{bc} 1}$ and $\xi_{\mathrm{dc} 1}$.

The analysis of correlations in Section 2.2 showed that only compressive strength $f_{\mathrm{cm}}$ and RCA content $R C A \%$ have significant correlations with the ratio of RAC-to-NAC creep. Thus, they were the only predicting variables considered for the correction factor At the same time, they are values regularly available to an engineer in the design stage (unlike, for example, water absorption). Since the comparisons of RAC and NAC in this study were only empirical, the optimal form for the correction factor $\xi_{\mathrm{cc}, \text { RAC }}$ was chosen as a bivariate power function:

$\xi_{c c, R A C}=x_{1} \cdot\left(f_{c m}\right)^{x_{2}} \cdot(R C A)^{x_{3}}$

Since the goal was to equalize MC2010's performance on RAC and companion NAC, it was necessary to increase the $\varphi_{\mathrm{MC}, \text { calc }} / \varphi_{\mathrm{MC} \text {,- }}$ exp ratio to 1.11 for all RCA contents, i.e. make it equal to NAC. First, for each RAC creep curve, after calculating the creep coefficient using MC2010, a unique value for $\xi_{\mathrm{cc}, \mathrm{RAC}}$ was calibrated for that curve to bring the $\varphi_{\mathrm{MC} \text {,calc }} / \varphi_{\mathrm{MC} \text {,exp }}$ ratio to 1.11 . This led to 31 unique calibrated $\xi_{\mathrm{cc}, \mathrm{RAC}}$ values (the remaining number of RAC creep curves)

Using the least squares method, the coefficients in Eq. (33) were fitted to match as closely as possible the values of the $\xi_{\mathrm{cc}, \mathrm{RAC}}$ coefficient determined for each creep curve separately. The correction factor $\xi_{\mathrm{cc}, \mathrm{RAC}}$ was obtained as

$\xi_{c c, R A C}=1.12 \cdot\left(f_{c m}\right)^{-0.15} \cdot(R C A)^{0.15}$

Using Eq. (34), the mean calculated-to-manually calibrated ratio for $\xi_{\mathrm{cc}, \mathrm{RAC}}$ was obtained as 1.07 with a $\mathrm{CoV}$ of $38.9 \%$. This is a reasonable result, considering the underlying scatter of the data. Since the correction factor was also calibrated for values smaller than 1.0, i.e. cases where RAC had a lower creep coefficient compared with NAC, the final version of the correction factor, intended as an extension of the MC2010 creep model, should never be smaller than 1.0 . Hence, $\xi_{\mathrm{cc}, \mathrm{RAC}}$ is finally proposed as

$\xi_{c c, R A C}=1.12 \cdot\left(\frac{R C A}{f_{c m}}\right)^{0.15} \geq 1.0$

In Eq. (35), $f_{\mathrm{cm}}$ should be in MPa and RCA\% in percentages.

Using this formulation of the correction factor, the CEB mean deviation for all RAC data is 1.04 and the CEB CoV $41.7 \%$. For different RCA percentages, the CEB mean deviation is $0.96,1.02,0.82$ and 1.24 for $1-25 \%, 26-50 \%, 51-75 \%$ and $76-100 \%$, respectively. The low value for $51-75 \%$ of RCA stems from the previously explained fact that this range contains mixtures produced with using the Equivalent Mortar Volume method, which are not fully representative of usual RAC mix design. The correction factor, thus, goes from an underestimation of performance relative to NAC (with $\left.M_{\mathrm{CEB}}=1.11\right)$ for RAC $1-75 \%(0.96,1.02,0.82)$, to an overestimation for RAC $76-100 \%$ (1.24). This is a consequence of the large scatter of the data - it cannot all be fitted simultaneously. Nonetheless, taking into consideration that the CEB mean deviations are within $10 \%$ of the value for NAC (except the 51-75\% RCA range) and the large CEB CoVs, there are no statistically significant differences between NAC and RAC, overall, at the 95\% significance level.

For illustration, the correction factor is plotted against RCA content in Fig. 7. It increases with increasing RCA percentage and decreasing compressive strength. For the usual range of compressive strengths of $20-60 \mathrm{MPa}$ the $\xi_{\mathrm{cc}, \mathrm{RAC}}$ ranges from 1.29 to 1.12 and 1.43 to 1.21 for RCA contents of $50 \%$ and $100 \%$, respectively (with higher values for $20 \mathrm{MPa}$ and lower values for $60 \mathrm{MPa}$ concretes).

Fig. 8 presents a scatter plot of calculated vs. experimental RAC creep coefficient, similar to Fig. 6 but with the RAC creep coefficient calculated using the correction factor $\xi_{\mathrm{cc}, \mathrm{RAC}}$. Relative to Fig. 6 , there is a shift of the mean line above the equality line, so that results are similar to NAC in Fig. 6.

The $\xi_{\text {cc,RAC }}$ coefficient in its form in Eq. (35) and the freely available database given as Supplementary material, can be easily updated and modified in the future - new studies and results can be added and new optimizations for the correction factor can be carried out.

Finally, everything that is stated in section 5.1.9.4.4 of the fib Model Code 2010 about analysing creep effects in reinforced NAC 

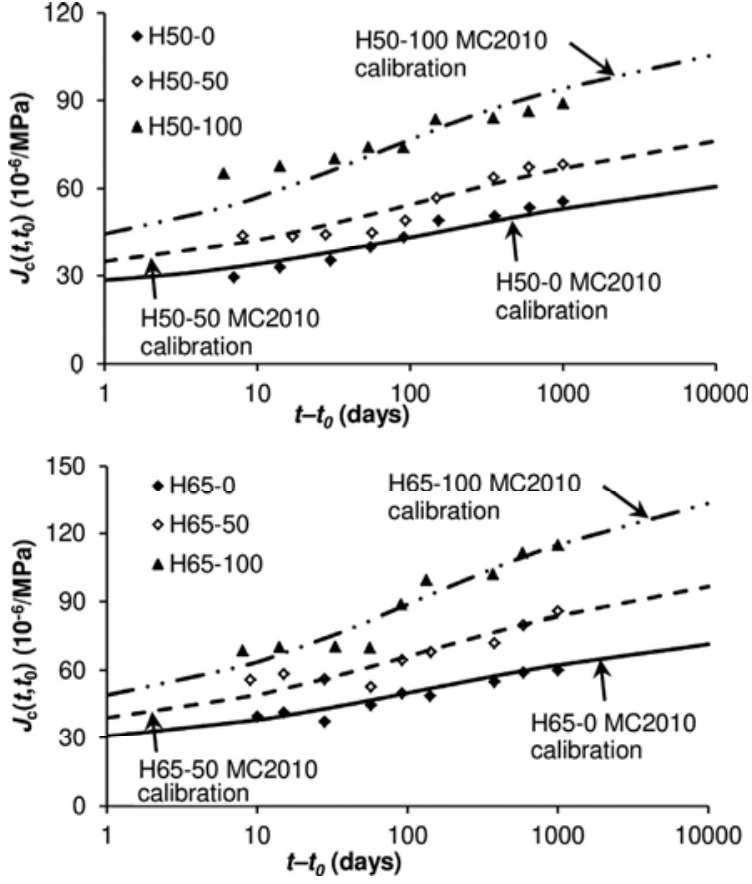

Fig. 5. Calibration of individual compliance curves from Seara-Paz (2015) [29].

Table 4

Statistical descriptors of the $\varphi_{\mathrm{MC}, \text { calc }} / \varphi_{\mathrm{MC}, \exp }$ ratio.

\begin{tabular}{llllll}
\hline \multirow{2}{*}{ RCA $\%$} & \multicolumn{2}{l}{ Full database } & & \multicolumn{2}{c}{ No calc/exp outliers } \\
\cline { 2 - 3 } \cline { 5 - 6 } & $\mu$ & $\operatorname{CoV}(\%)$ & & $\mu$ & $\operatorname{CoV}(\%)$ \\
\hline 0 (NAC) & 1.27 & 54.8 & & 1.11 & 44.4 \\
$1-25$ & 0.95 & 24.1 & & 0.94 & 23.1 \\
$26-50$ & 0.92 & 48.8 & & 0.92 & 48.3 \\
$51-75$ & 0.69 & 23.1 & & 0.69 & 23.1 \\
$76-100$ & 0.96 & 42.0 & & 0.96 & 42.0 \\
\hline
\end{tabular}

structures [11], is also true for RAC. Because of its similar scatter, more detailed analysis should include taking the $10 \%$ and $5 \%$ cutoff values of the creep coefficient, assuming a normal distribution. However, with this approach, the cut-off value needs to be formed from the creep coefficient $\varphi_{\mathrm{MC}, \mathrm{RAC}}\left(t, t_{0}\right)$ as given in Eq. (32). Just as for NAC structures, if the design with these cut-off values does not provide satisfactory results, tests and calibrations of the model, according to Eqs. (12), (15) and (20) should be performed.

\section{Conclusions}

This study presented a meta-analysis of previously published results on the creep behaviour of RAC through the formation of a database of RAC and companion NAC creep coefficient. Using statistical analyses, comparisons were made between the creep behaviour of RAC and companion NAC and between the predictions by the fib Model Code 2010 for the RAC and companion NAC creep coefficient. Considering the significant scatter of experimental creep results, which brings uncertainties into creep coefficient calculations using all existing models including MC2010, the following conclusions can be drawn:

1. After reviewing existing literature on RAC creep and applying clear and strict criteria, only 10 studies were identified which provide all necessary data for comparisons and analysis of
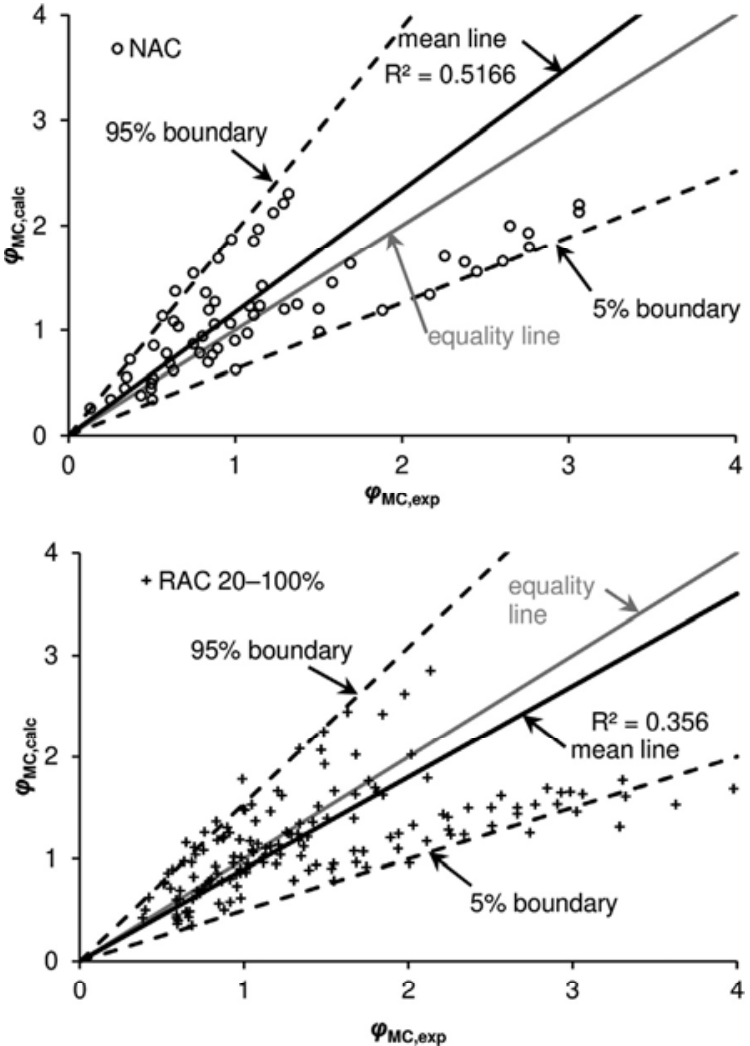

Fig. 6. Calculated vs. experimental NAC and RAC MC2010 creep coefficient values with eliminated outliers.

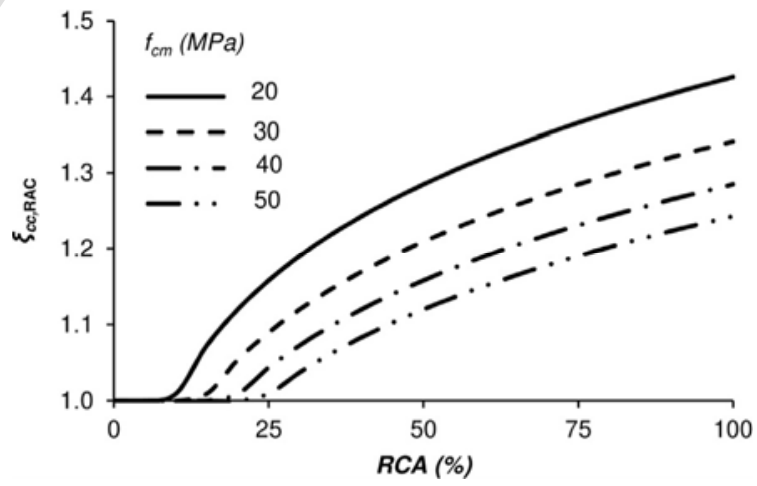

Fig. 7. Correction coefficient $\xi_{\mathrm{cc}, \mathrm{RAC}}$ for different compressive strengths and RCA contents.

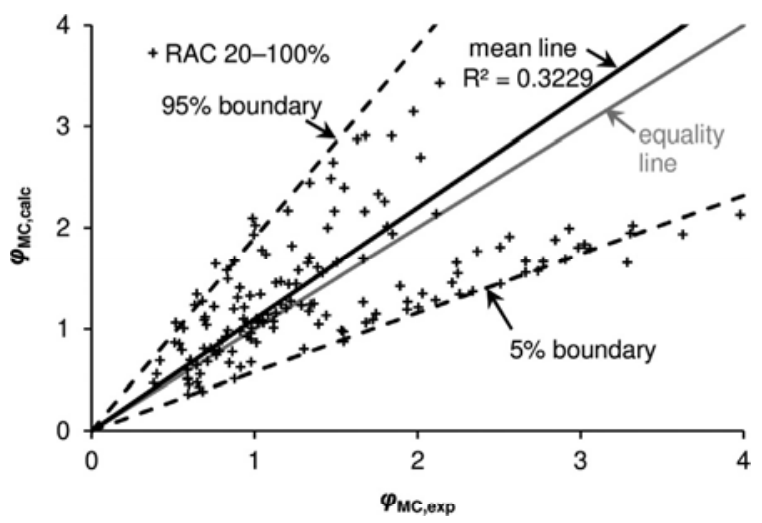

Fig. 8. Calculated vs. experimental MC2010 creep coefficient of RAC using the $\xi_{\mathrm{cc}, \mathrm{RAC}}$ correction factor 
RAC and companion NAC creep. In total, 10 studies with 46 creep time curves (14 NAC and $32 \mathrm{RAC}$ ) and 233 data points were selected for the database which is freely available as Supplementary material;

2. Comparing RAC and NAC MC2010 creep coefficients, through the $\varphi_{\mathrm{MC}, \exp , \mathrm{RAC}} / \varphi_{\mathrm{MC}, \exp , \mathrm{NAC}}$ ratio, showed that, on average, RAC has a larger creep coefficient than a companion NAC concrete (having an identical $(w / c)_{\text {eff }}$ ratio). The differences between RAC and companion NAC are only in the magnitude of the creep coefficient, i.e. RAC creep compliance curves are vertically scaled compared with companion NAC creep compliance curves. The current database did not reveal different time evolution of RAC creep compared with companion NAC; more experiments separating RAC creep into basic and drying components are necessary;

3. Although the variability in the database is large, the difference between RAC and companion NAC creep can be shown to increase with increasing RCA content and decreasing compressive strength. For RAC with $100 \%$ of RCA, the average increase of the creep coefficient is $39 \%$ relative to companion NAC;

4. Fitting the prediction of the fib Model Code 2010 creep model to individual RAC creep compliance curves confirmed that the model's mathematical form enables an accurate qualitative description of the time evolution of RAC creep compliance. However, applying the MC2010 model with its default parameter values on the RAC database revealed that it underestimates the RAC creep coefficient;

5. A creep coefficient correction factor $\xi_{\mathrm{cc}, \mathrm{RAC}}$ for RAC was formulated as a bivariate power function with RCA content and RAC compressive strength as predicting variables. The correction factor should be used to multiply the MC2010 creep coefficient $\varphi_{\mathrm{MC}}\left(t, t_{0}\right)$. The correction factor is practical and easy to use because the required inputs are always available during the design stage.

All of the above stated conclusions depend upon the database from which they were drawn and are valid only within the current range of parameters. Nonetheless, since the database is freely available online, it will be easy for the research community to update it, improve it, and analyse it in new and different ways compared with the ones presented in this study.

\section{Acknowledgements}

This work was supported by the Ministry for Education, Science and Technology, Republic of Serbia [grant number TR36017] and the SAES project [BIA2016-78742-C2-1-R] of the Spanish Ministerio de Economía, Industria y Competitividad. This support is gratefully acknowledged.

\section{Conflict of interest}

None.

\section{References}

[1] P. Acker, F.J. Ulm, Creep and shrinkage of concrete: physical origins and practical measurements, Nucl. Eng. Des. 203 (2001) 143-158.

[2] G. Pickett, The effect of change in moisture-content on the creep of concrete under a sustained load, J. Am. Concr. Inst. 13 (1942) 333-355, https://doi.org/ $10.14359 / 8607$

[3] W.K. Hatt, Notes on the effect of time element in loading reinforced concrete beams, in: Proc. ASTM, 1907, pp. 421-433.

[4] T.C. Powers, The thermodynamics of volume change and creep, Mater. Struct. 1 (1968) 487-507, https://doi.org/10.1007/BF02473638.

[5] M. Vandamme, F.-J. Ulm, Nanogranular origin of concrete creep, Proc. Natl Acad. Sci. U.S.A. 106 (2009) 10552-10557, https://doi.org/10.1073/ pnas. 0901033106 .
[6] Z.P. Bažant, A.B. Hauggaard, S. Baweja, F. Ulm, Microprestress-solidification theory for concrete creep. I: Aging and drying effects, J. Eng. Mech. 123 (1997) 1188-1194, https://doi.org/10.1061/(ASCE)0733-9399(1997)123:11(1188).

[7] Z.P. Bažant, S. Baweja, Justification and refinements of Model B3 for concrete creep and shrinkage 1 . Statistics and sensitivity, Mater. Struct. 28 (1995) 415 430.

[8] Z.P. Bažant, M.H. Hubler, R. Wendner, RILEM draft recommendation: TC-242MDC multi-decade creep and shrinkage of concrete: material model and structural analysis, Mater. Struct. 48 (2015) 753-770, https://doi.org/10.1617/ s11527-014-0485-2.

[9] ACI 209R-92, Prediction of Creep, Shrinkage, and Temperature Effects in Concrete Structures, American Concrete Institute, Farmington Hills, MI, 1992.

[10] EN 1992-1-1, Eurocode 2: Design of Concrete Structures - Part 1-1: General Rules and Rules for Buildings, CEN, Brussels, 2004.

[11] FIB, in: fib Model Code for Concrete Structures 2010, International Federation for Structural Concrete (fib), Lausanne, 2013, https://doi.org/10.1002/ 9783433604090.

[12] R. Wendner, M.H. Hubler, Z.P. Bažant, Statistical justification of model B4 for multi-decade concrete creep using laboratory and bridge databases and comparisons to other models, Mater. Struct. 48 (2015) 815-833, https://doi. org/10.1617/s11527-014-0486-1.

[13] CEB-FIP, Model Code 1978, Comite Euro-International Du Beton, Paris, 1978

[14] M.H. Hubler, R. Wendner, Z.P. Bažant, Comprehensive database for concrete creep and shrinkage: analysis and recommendations for testing and recording. ACI Mater. J. 112 (2015) 547-558, https://doi.org/10.14359/51687453.

[15] M.F. Ruiz, A. Muttoni, P.G. Gambarova, Relationship between nonlinear creep and cracking of concrete under uniaxial compression, J. Adv. Concr. Technol. 5 (2007) 383-393.

[16] N. Reybrouck, P. Criel, T. Van Mullem, R. Caspeele, Long-term data of reinforced concrete beams subjected to high sustained loads and simplified prediction method, Struct. Concr. 18 (2017) 850-861, https://doi.org/ 10.1002 /suco.201700040.

17] G. Fathifazl, G. Razaqpur, Creep rheological models for recycled aggregate concrete, ACI Mater. J. 2 (2013) 115-125.

[18] R.V. Silva, Use of Recycled Aggregates from Construction and Demolition Waste in the Production of Structural Concrete, Universidade de Lisboa, 2015

[19] RILEM TC 121-DRG, RILEM recommendation: specifications for concrete with recycled aggregates, Mater. Struct. 27 (1994) 557-559.

[20] C.Q. Lye, R.K. Dhir, G.S. Ghataora, H. Li, Creep strain of recycled aggregate concrete, Constr. Build. Mater. 102 (2016) 244-259, https://doi.org/10.1016 j.conbuildmat.2015.10.181.

[21] Y. Fan, J. Xiao, V.W.Y. Tam, Effect of old attached mortar on the creep of recycled aggregate concrete, Struct. Concr. 15 (2014) 169-178.

[22] S. Seara-Paz, B. González-Fonteboa, F. Martínez-Abella, I González-Taboada, Time-dependent behaviour of structural concrete made with recycled coarse aggregates. Creep and shrinkage, Constr. Build. Mater. 122 (2016) 95-109, https://doi.org/10.1016/j.conbuildmat.2016.06.050.

[23] J.O. Castaño, A. Domingo, C. Lazaro, A study on drying shrinkage and creep of recycled concrete aggregate, in: Proc. Int. Assoc. Shell Spat. Struct. Symp. 2009 2009, pp. 2955-2964

[24] A. Domingo, C. Lázaro, F.L. Gayarre, M.A. Serrano, C. López-Colina, Long term deformations by creep and shrinkage in recycled aggregate concrete, Mater Struct. 43 (2010) 1147-1160, https://doi.org/10.1617/s11527-009-9573-0.

[25] G. Fathifazl, A. Ghani Razaqpur, O. Burkan Isgor, A. Abbas, B. Fournier, S. Foo, Creep and drying shrinkage characteristics of concrete produced with coarse recycled concrete aggregate, Cem. Concr. Compos. 33 (2011) 1026-1037, https://doi.org/10.1016/j.cemconcomp.2011.08.004.

[26] S. Manzi, C. Mazzotti, M.C. Bignozzi, Short and long-term behavior of structura concrete with recycled concrete aggregate, Cem. Concr. Compos. 37 (2013) 312-318, https://doi.org/10.1016/j.cemconcomp.2013.01.003.

[27] S.C. Paul, G.P.A.G. van Zijl, Mechanical and durability properties of recycled concrete aggregate for normal strength structural concrete, Int. J. Sustain Constr. Eng. Technol. 4 (2013) 89-103.

[28] R. Sri Ravindrarajah, C.T. Tam, Properties of concrete made with crushed concrete as coarse aggregate, Mag. Concr. Res. 37 (1985) 29-38, https://doi. org/10.1680/macr.1985.37.130.29.

[29] S. Seara-Paz, Efect of Long-term Deformations in Structural Flexural Performance and Bond Behaviour Analysis of Recycled Concrete, Universidade de Coruna, 2015

[30] A. Gholampour, T. Ozbakkaloglu, Time-dependent and long-term mechanical properties of concretes incorporating different grades of coarse recycled concrete aggregates, Eng. Struct. 157 (2018) 224-234, https://doi.org/10.1016 j.engstruct.2017.12.015.

[31] A. Al-Manaseer, A. Prado, Statistical comparisons of creep and shrinkage prediction models using RILEM and NU-ITI databases, ACI Mater. J. 112 (2015) $125-135$.

[32] ACI 209.2R-08, Guide for Modeling and Calculating Shrinkage and Creep in Hardened Concrete, American Concrete Institute, Farmington Hills, MI, 2008.

[33] M.H. Hubler, R. Wendner, Z.P. Bažant, Statistical justification of Model B4 for drying and autogenous shrinkage of concrete and comparisons to other models, Mater. Struct. 48 (2015) 797-814, https://doi.org/10.1617/s11527014-0516-z.

[34] PT1 prEN1992-1-1, Eurocode 2: Design of Concrete Structures - Part 1-1 General Rules, Rules for Buildings, Bridges and Civil Engineering Structures, CEN, Brussels, 2017. 